\title{
Increased Incidence of Functional (Psychogenic) Movement Disorders in Children and Adults Amid the COVID-19 Pandemic
}

\author{
A Cross-sectional Study
}

Mariam Hull, MD, Mered Parnes, MD, and Joseph Jankovic, MD

Neurology: Clinical Practice October 2021 vol. 11 no. 5 e686-e690 doi:10.1212/CPJ.0000000000001082

Correspondence

Dr. Hull

mariam.hull@bcm.edu

\begin{abstract}
\section{Background and Objectives}

Functional (psychogenic) movement disorders (FMDs) are conditions in which affected patients develop abnormal movements that are incongruous with known, organic, movement disorders, often associated with psychological stressors.
\end{abstract}

\section{Methods}

In this case series, electronic medical records of all patients who presented to our adult and pediatric tertiary care movement disorders clinics between March 1 and October 30, 2020, and during the same period in 2019 were reviewed. All patients diagnosed with functional

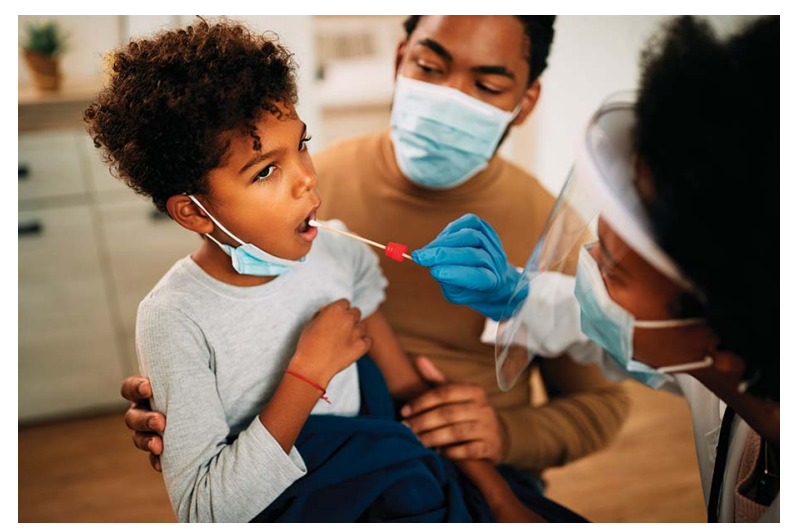
(psychogenic) movement disorder were included if they satisfied diagnostic criteria.

\section{Results}

Among 550 new patients referred for evaluation at our tertiary care movement disorders centers, 45 (8.2\%) received a diagnosis of FMD; $75.6 \%$ were female, in comparison to the prior year during which time 665 new patients were evaluated and 5.1\% were diagnosed with FMD. This represents a $60.1 \%$ increase $(90.1 \%$ in pediatric cohort, $50.9 \%$ in adult cohort) in new patients diagnosed with FMD during the COVID-19 pandemic.

\section{Conclusions}

Within our patient population, there has been increased incidence of FMDs in the setting of the COVID-19 pandemic, possibly reflecting increased psychological and other stressors during this period.

\section{MORE ONLINE}

COVID-19 Resources

For the latest articles, invited commentaries, and blogs from physicians around the world NPub.org/COVID19

In December 2019, cases of a novel respiratory virus, later named severe acute respiratory syndrome coronavirus 2, were reported in Wuhan, China. ${ }^{1}$ Soon thereafter, the disease caused by the virus, COVID-19, became a worldwide pandemic. Globally, regulations were put in place to mitigate the spread of the virus and research efforts aimed at management and treatment of the disease were initiated. ${ }^{1}$

Initially, COVID-19 was thought to be a disease primarily involving the respiratory system with nonspecific neurologic symptoms such as headaches, fatigue, and dizziness, but it was soon recognized to be a multisystem disease. ${ }^{2}$ A systematic surveillance study revealed that

Section of Pediatric Neurology and Developmental Neuroscience (MH, MP), Texas Children's Hospital and Baylor College of Medicine; and Department of Neurology (MH, MP, J), Parkinson's Disease Center and Movement Disorders Clinic, Baylor College of Medicine, Houston, TX.

Funding information and disclosures are provided at the end of the article. Full disclosure form information provided by the authors is available with the full text of this article at Neurology.org/cp. 
neurologic and psychiatric involvement is common but variable, and manifested by cerebral vasculitis, stroke (ischemic and hemorrhagic), encephalitis, Guillain-Barre syndrome, psychosis, dementia, catatonia, and mania. ${ }^{3}$

At the time of this writing, the full psychological effect of the COVID-19 pandemic is just beginning to be understood. During the initial peak of the pandemic in China, patients previously diagnosed with depression and anxiety disorders reported an increase in symptoms of posttraumatic stress disorder, anxiety, depression, and insomnia. ${ }^{4}$ In a series of 4 consecutive patients admitted for new onset of reactive psychosis during the first 2 weeks of compulsory nationwide quarantine in Spain, all the episodes were linked to stressors from the COVID-19 pandemic. $^{5}$

Functional (psychogenic) movement disorders (FMDs) are a common presentation within the broader category of functional neurologic symptom disorder, previously called conversion disorder, hysterical neurosis, somatoform disorder, dissociative disorder, and psychogenic disorder. ${ }^{6,7}$ In the Diagnostic and Statistical Manual of Mental Disorders, 5th Edition, this diagnosis falls within the somatic symptom and related disorders. FMD appears to be a manifestation of a dysfunctional manner of coping with underlying psychological stressors, ${ }^{8}$ although a particular underlying stressor is not always determined and is not necessary to make the diagnosis.

Although the psychological effect of this pandemic is increasingly being recognized, the full spectrum of manifestations of coping with the psychological stressors has yet to be fully realized. Here, we describe the effect of the COVID-19 pandemic within the field of movement disorders to draw attention to a marked increase of new patients presenting to movement disorders clinics with FMDs compared with the preceding year.

\section{Methods}

A total of 550 new patients were evaluated at our movement disorders clinics from March 1 to October 30, 2020, and 665 new patients were evaluated from March 1 to October 30, 2019. All patients who received a diagnosis of FMD as previously defined ${ }^{8}$ were included, and clinical documentation was reviewed. Demographics, diagnostic studies, medical history, and clinical examination were evaluated. We excluded patients for whom alternative diagnoses were proposed. Basic statistical methods used include calculation of mean and range. Percentage of patients receiving new diagnoses of FMD was calculated in each group and within the total number of patients for 2019 and 2020, and percent change of incidence between each year in provided groups was also calculated using total number of new patients evaluated at our centers. Comparison of proportions was calculated between the groups in 2019 and 2020 using a $\chi^{2}$ test to calculate $p$ values.

\section{Standard Protocol Approvals, Registrations, and Patient Consents}

Research was performed under the regulations placed by the respective institutional ethics committees.

\section{Data Availability}

Anonymized data not published within this article will be made available by request from any qualified investigator.

\section{Results}

Among 550 new patients (132 at the pediatric movement disorders clinic) evaluated at our movement disorders centers, 45 (12 pediatric and 33 adult) received a new diagnosis of FMD (8.2\%) from March 1 to October 30, 2020. This is in contrast to 665 new patients evaluated ( 168 pediatric and 497 adult) in the prior year, during which only 34 (5.1\%) were diagnosed with FMD ( 8 pediatric and 26 adult). This represents a $60.1 \%$ increase $(p=0.029,95 \%$ confidence interval $0.27 \%-6.02 \%)(90.1 \%$ in the pediatric cohort and $50.9 \%$ in the adult cohort) in new patients diagnosed with FMD during the COVID-19 pandemic (figure 1).

The average age at presentation was 34.2 years (13.9 years pediatric and 41.6 years adult). Adult clinic cohort range of age at presentation ranged from 9 to 77 years, and pediatric clinic cohort age at presentation ranged was 9 to 17 years. Females presenting with FMD comprised $75.6 \%$ of those diagnosed $(\mathrm{N}=34)$. Of the patients newly diagnosed with FMD, $62.2 \%$ had at least 1 prior psychiatric diagnosis $(\mathrm{N}=$ 28 ), whereas $42.2 \%$ had a preexisting medical condition $(\mathrm{N}=$ 19) (figure 2). Clear precipitating factors were identified in $48.9 \%(\mathrm{~N}=22)$ of patients.

Unique triggers identified in our cohort included 1 patient who developed functional tremor while hospitalized for COVID-19. Another patient developed functional tics after watching a teenager on TikTok (a social media platform) displaying and discussing her own diagnosis of "Tourette syndrome."

The most common phenomenologic classification of FMD was tremor, followed by dystonia (table). The mean duration of symptoms was 60.7 months (range: 1-468 months).

\section{Discussion}

Although the neurologic and psychological impacts of COVID-19 are currently being studied and many well described to include cerebral vasculitis, stroke, encephalitis, Guillain-Barre syndrome, and others, ${ }^{1}$ the impact of the disease on neurologic movement disorders has been restricted to case reports including myoclonus, tremor, ataxia, and parkinsonism. ${ }^{9-12}$

FMD is a common diagnosis in specialty movement disorders referral centers, and can be difficult to distinguish from 
Figure 1 Total Number of New Patients Presenting to Movement Disorders Clinics (March 1 to October 30) in 2019 vs 2020 Diagnosed With FMD (Functional Movement Disorders)

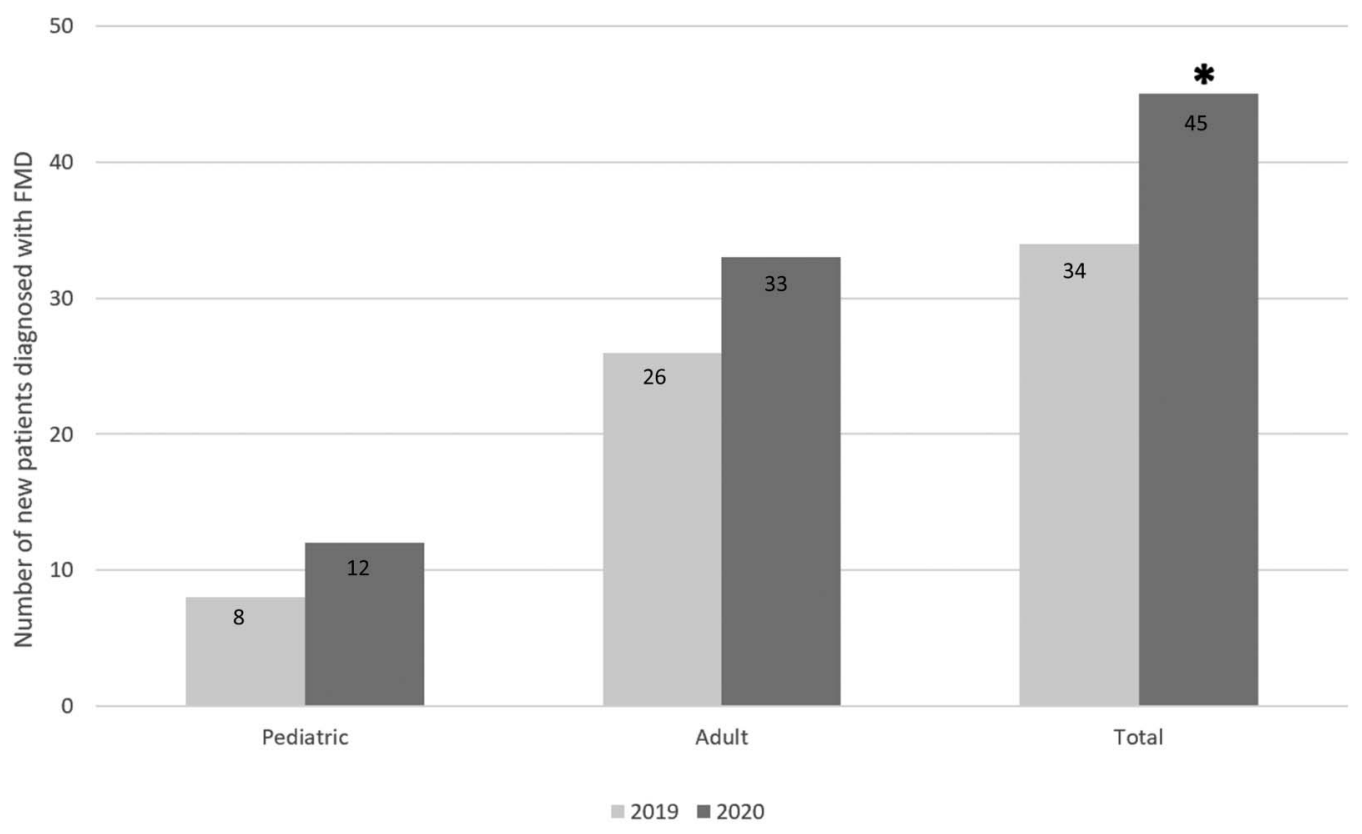

* $p=0.029$ when comparing total number of new patients diagnosed with FMD in 2020 vs 2019.

organic conditions, especially for clinicians with less movement disorders expertise. ${ }^{8,13}$ Thorough history taking often elicits characteristic features such as an abrupt onset with rapid progression to maximum severity, paroxysmal or episodic symptoms with symptom-free periods between episodes (including associated mutism, stuttering, or other episodic impairments of speech or language production), unusual triggers (e.g., psychological or physical trauma, flashing lights, physical touch, proximity to people or objects, and loud noises), or many seemingly unrelated neurologic symptoms, which may change over time. Examination also typically demonstrates supportive signs such as distractibility, suggestibility, and variability in frequency, pattern, and/ or amplitude, among others. ${ }^{6,8,13,14}$ The existence of a pattern of positive symptoms and signs on history and examination, rather than the absence of another etiology, is crucial in making the diagnosis.

Limitations of this study include potential for recall bias given the method being a cross-sectional study; therefore, similar time periods were chosen from the year prior. Furthermore, as our centers are specialized movement disorders centers, patients are often preselected for evaluation within these clinics with a chief complaint of abnormal movements, which results in a higher rate of FMDs and as such may not necessarily be generalizable to non-subspecialized centers. Last, during the time period in 2020, our clinics (among numerous others) adopted telemedicine as an option for clinical evaluation, which may also have preselected patients with access to such technology, and due to the COVID-19 pandemic, some patients may have elected to postpone any clinical evaluations.
The underlying pathophysiology of FMDs remains unclear, but our understanding of possible mechanisms has been improving as result of growing interest and research advances. ${ }^{6,14}$ The relationship to stress as a potential precipitating factor is supported by our finding of increased incidence of FMD cases during the challenging pandemic. We propose that differences between the pediatric and the adult cohorts may be due to underlying differences in cognitive coping strategies between the 2 populations. ${ }^{15}$

Organic brain differences have been noted among patients with FMDs compared with unaffected controls, including altered connectivity between the limbic and motor networks. ${ }^{16-19}$ Patients with FMD have been found to have decreased activation of the supplementary motor area in comparison to controls. Furthermore, patients with functional neurologic symptom disorder appear to have increased connectivity between the insula, inferior frontal gyrus, parietal cortex, and precentral sulcus (areas involved with emotion, executive planning, and movement). ${ }^{16}$ Although the pathophysiology of FMDs is still not fully understood, exposures to trauma (physical and/or psychological) have been proposed to reshape the connectivity until a threshold is reached after which a motor response is manifested. ${ }^{20-24}$

Prior outbreaks including Zika, Ebola, avian influenza, and H1N1 have been found to cause psychological stress within the population. ${ }^{25}$ Early data suggest that COVID-19 has also been the cause of increased psychological morbidity ${ }^{4,5}$ including increased feelings of anxiety and symptoms in patients with a prior diagnosis of FMD. ${ }^{26}$ To date, there is 
Figure 2 Preexisting Psychiatric Diagnoses of Patients Presenting With Functional Movement Disorder (FMD) to Movement Disorders Clinics (March 1-October 30, 2020)

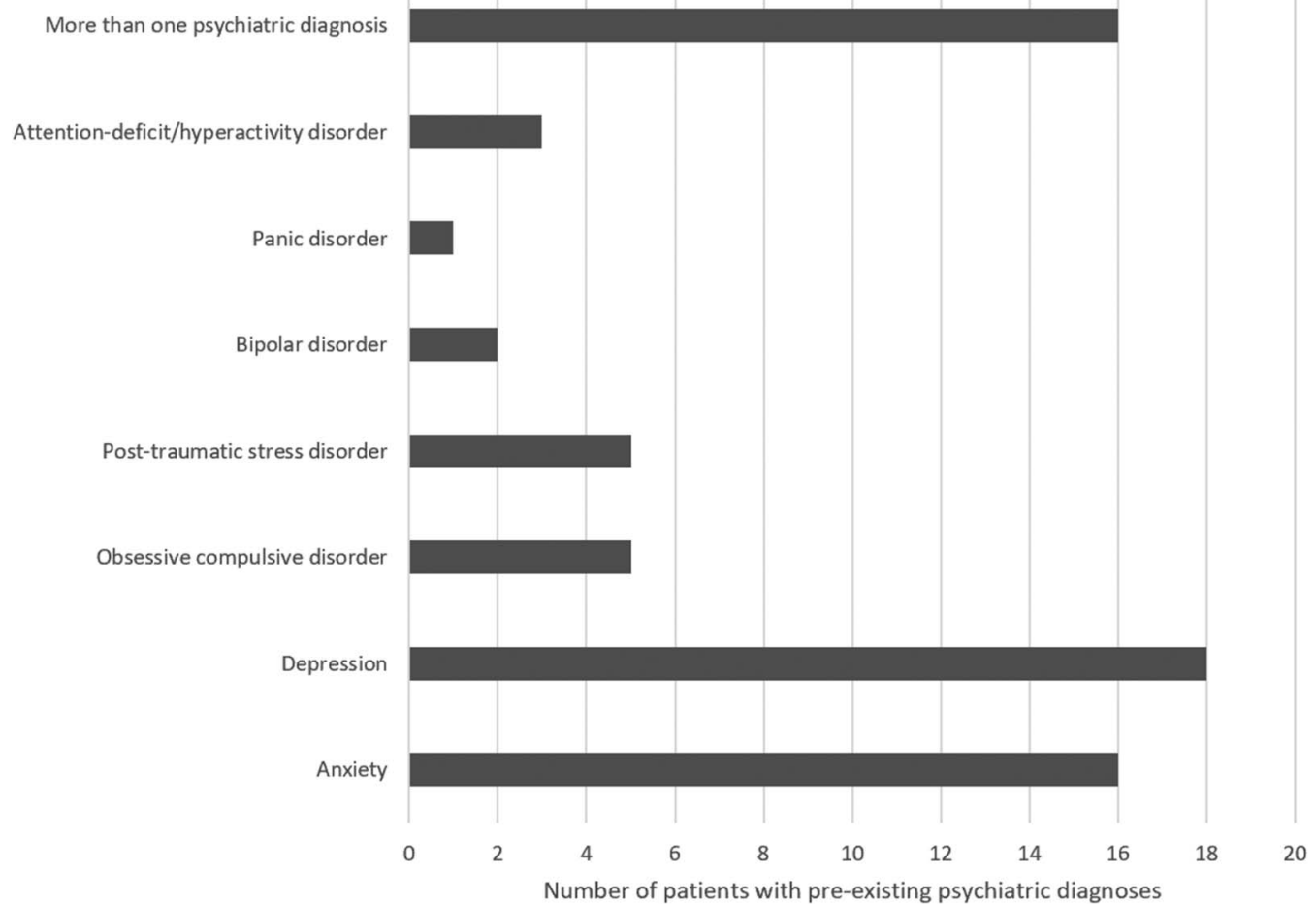

1 report of a patient who developed FMD while quarantined with the disease. ${ }^{25}$ One of the patients included in our adult cohort developed FMD while hospitalized for symptoms of COVID-19.

Effects on the population since the onset of the outbreak include job losses, school closures, and increased feelings of loneliness and isolation; many have endorsed new feelings of increased anxiety, depression, and stress. ${ }^{27}$ These feelings can persist through the periods of recovery from an outbreak, as has been reported with the resolution of SARS in Taiwan. ${ }^{15}$

Table Total Number of Patients With Functional Movement Disorder, Classified by Presenting Phenomenology

\begin{tabular}{lll}
\hline Classification & Number & Percentage \\
\hline Tremor & 24 & 53.3 \\
\hline Dystonia & 14 & 31.1 \\
\hline Myoclonus & 8 & 17.8 \\
\hline Tics & 4 & 8.9 \\
\hline Stereotypy & 4 & 8.9 \\
\hline Multiple & 9 & 20.0 \\
\hline
\end{tabular}

The first reports of widespread functional neurologic symptom disorder in a population were in the context of mass psychogenic illness (mass hysteria) surrounding the bubonic plague pandemic known as the Black Death, in $1374 \mathrm{AD} .^{28,29}$ More recent reports of mass psychogenic illness have primarily involved close-knit groups of adolescent females. ${ }^{28}$ In 2012, a group of girls in a school in Le Roy, New York, developed acute onset functional tics, and many of the girls found themselves as popular faces of social media. ${ }^{30}$

The role of social media within functional neurologic symptom disorder and FMD is unclear; however, during a pandemic of which there is implementation of social distancing, there does seem to be increased use of the various social media platforms (up to $82 \%$ of participants in 1 study reported frequent social media exposure). ${ }^{30}$ In this study, social media exposure was also correlated with higher odds of anxiety and depression. One of the patients within our cohort also presented with the abrupt onset of functional tics after watching a social media personality on TikTok who had been diagnosed with Tourette syndrome; our patient acutely developed similar movements and noises. We suggest that functional tics developing after watching similar movements on social media platforms be referred to as TikTok tics. We expect that in the advent of increased utilization of social media during the pandemic, these types of presentations may become more common.

We describe increased incidence of FMDs within our movement disorders centers in the setting of the COVID-19 
$\rightarrow$ Functional (psychogenic) movement disorder is a relatively common condition encountered within movement disorders centers and has often been associated with psychological stressors.

$\rightarrow$ During the COVID-19 pandemic, there has been an observed increase incidence within our centers.

$\rightarrow$ The full psychological effects of the COVID-19 pandemic have yet to be fully realized, however, stresses related to social isolation, financial strain, and other pandemic-related burdens may contribute to our observed increase in incidence of functional movement disorders.

pandemic in both the pediatric and adult age groups. Although specific stressors are not always evident and are not necessary to make the diagnosis, the current rise in incidence of FMDs may support the role of psychological stressors related to social isolation, financial strain, and other pandemic-related burdens within this disorder.

\section{Study Funding}

No targeted funding reported.

\section{Disclosure}

M. Parnes has served on a Scientific Advisory or Data Safety Monitoring board for Teva Pharmaceuticals. The institution of Dr. Parnes has received research support from the NIH and Alexion. M. Hull and J. Jankovic report no disclosures relevant to the manuscript. Full disclosure form information provided by the authors is available with the full text of this article at Neurology.org/cp.

\section{Publication History}

Received by Neurology: Clinical Practice November 19, 2020. Accepted in final form February 19, 2021.

\section{Appendix Authors}

\begin{tabular}{|c|c|c|}
\hline Name & Location & Contribution \\
\hline $\begin{array}{l}\text { Mariam Hull, } \\
\text { MD }\end{array}$ & $\begin{array}{l}\text { Section of Pediatric } \\
\text { Neurology and } \\
\text { Developmental } \\
\text { Neuroscience, Texas } \\
\text { Children's Hospital and } \\
\text { Baylor College of Medicine, } \\
\text { Houston }\end{array}$ & $\begin{array}{l}\text { Drafting/revision of the } \\
\text { manuscript for content, } \\
\text { including medical writing for } \\
\text { content; major role in the } \\
\text { acquisition of data; study } \\
\text { concept or design; and } \\
\text { analysis or interpretation of } \\
\text { data }\end{array}$ \\
\hline $\begin{array}{l}\text { Mered } \\
\text { Parnes, MD }\end{array}$ & $\begin{array}{l}\text { Department of Neurology, } \\
\text { Parkinson's Disease } \\
\text { Center and Movement } \\
\text { Disorders Clinic, Baylor } \\
\text { College of Medicine, } \\
\text { Houston, TX }\end{array}$ & $\begin{array}{l}\text { Drafting/revision of the } \\
\text { manuscript for content, } \\
\text { including medical writing for } \\
\text { content, and study concept } \\
\text { or design }\end{array}$ \\
\hline
\end{tabular}

\begin{tabular}{|c|c|c|}
\hline Name & Location & Contribution \\
\hline $\begin{array}{l}\text { Joseph } \\
\text { Jankovic, MD }\end{array}$ & $\begin{array}{l}\text { Department of Neurology, } \\
\text { Parkinson's Disease Center } \\
\text { and Movement Disorders } \\
\text { Clinic, Baylor College of } \\
\text { Medicine, Houston, TX }\end{array}$ & $\begin{array}{l}\text { Drafting/revision of the } \\
\text { manuscript for content, } \\
\text { including medical writing for } \\
\text { content }\end{array}$ \\
\hline
\end{tabular}

\section{References}

1. Hopkins Tanne J, Hayasaki E, Zastrow M, et al. Covid-19: how doctors and healthcare systems are tackling coronavirus worldwide as coronavirus continues to spread, doctors and healthcare systems are facing a multitude of challenges at all stages of the pandemic. BMJ. 2020;368:1-5

2. Gupta A, Madhavan MV, Sehgal K, et al. Extrapulmonary manifestations of COVID19. Nat Med. 2020;26:1017-1032.

3. Varatharaj A, Thomas N, Ellul MA, et al. Neurological and neuropsychiatric complications of COVID-19 in 153 patients: a UK-wide surveillance study. Lancet Psychiatry. 2020;7:875-882.

4. Hao F, Tan W, Jiang L, et al. Do psychiatric patients experience more psychiatric symptoms during COVID-19 pandemic and lockdown? A case-control study with service and research implications for immunopsychiatry. Brain Behav Immun. 2020;87: 100-106.

5. Valdés-Florido MJ, López-Díaz Á, Palermo-Zeballos FJ, et al. Reactive psychoses in the context of the COVID-19 pandemic: clinical perspectives from a case series PALABRAS CLAVE. Rev Psiquiatr Salud Ment (Barc). 2020;13:90-94.

6. Hallett M. Functional (psychogenic) movement disorders-clinical presentations. Parkinsonism Relat Disord. 2016;22:149-152.

7. Trimble M, Reynolds EH. A brief history of hysteria: from the ancient to the modern. Handbook Clin Neurol. 2016;139:3-10.

8. Thenganatt MA, Jankovic J. Psychogenic movement disorders. Neurol Clin. 2015;33:205-224.

9. Diezma-Martín AM, Morales-Casado MI, García-Alvarado N, Vadillo Bermejo A, López-Ariztegui N, Sepúlveda Berrocal MA. Tremor and ataxia in COVID-19. Neurologia. 2020;35:409-410.

10. Méndez-Guerrero A, Laespada-García IM, Gómez-Grande A, et al. Acute hypokinetic-rigid syndrome following SARS-CoV-2 infection. Neurology. 2020;95: e2109-e2118.

11. Khoo A, McLoughlin B, Cheema S, et al. Postinfectious brainstem encephalitis associated with SARS-CoV-2. J Neurol Neurosurg Psychiatry. 2020;91:1013-1014.

12. Rábano-Suárez P, Bermejo-Guerrero L, Méndez-Guerrero A, et al. Generalized myoclonus in COVID-19. Neurology. 2020;95:e767-e772.

13. Mink JW. Conversion disorder and mass psychogenic illness in child neurology. Ann N Y Acad Sci. 2013;1304:40-44.

14. Perez DL, Aybek S, Popkirov S, et al. A review and expert opinion on the neuropsychiatric assessment of motor functional neurological disorders. J Neuropsychiatry Clin Neurosci. 2021;33:14-26.

15. Garnefski N, Legerstee J, Kraaij V, Van T, Teerds J. Cognitive coping strategies and symptoms of depression and anxiety: a comparison between adolescents and adults. J Adolescence. 2002;25:603-611.

16. Espay AJ, Aybek S, Carson A, et al. Current concepts in diagnosis and treatment of functional neurological disorders. JAMA Neurol. 2018;75:1132-1141.

17. Aybek S, Nicholson TR, O'daly O, Zelaya F, Kanaan RA, David AS. Emotion-motion interactions in conversion disorder: an fMRI Study. PLoS One. 2015;10:1-11.

18. Ospina JP, Jalilianhasanpour R, Perez DL. The role of the anterior and middle cingulate cortices in the neurobiology of functional neurological disorder. Handb Clin Neurol. 2019;166:267-279.

19. Maurer CW, Lafaver K, Ameli R, Epstein SA, Hallett M, Horovitz SG. Impaired self-agency in functional movement disorders A resting-state AMRI study. Neurology. 2016;87:564-570.

20. Blakey SM, Abramowitz JS. Psychological predictors of health anxiety in response to the Zika virus. J Clin Psychol Med Settings. 2017;24:270-278.

21. Blakey SM, Reuman L, Jacoby RJ, Abramowitz JS. Tracing “"Fearbola”: psychological predictors of anxious responding to the threat of Ebola. Cogn Ther Res. 2015;39:816-825.

22. Lau JTF, Kim JH, Tsui HY, Griffiths S. Perceptions related to bird-to-human avian influenza, influenza vaccination, and use of face mask. Infection. 2008;36:434-443.

23. Goodwin R, Gaines SO, Myers L, Neto F. Initial psychological responses to swine flu. Int Soc Behav Med. 2011;18:88-92.

24. Bults M, Beaujean DJMA, de Zwart O, et al. Perceived risk, anxiety, and behavioural responses of the general public during the early phase of the Influenza A (H1N1) pandemic in the Netherlands: results of three consecutive online surveys. BMC Public Health. 2011;11:2

25. Piscitelli D, Perin C, Tremolizzo L, et al. Functional movement disorders in a patient with COVID-19. Neurol Sci. 2020;41:2343-2344.

26. Delgado C, Pareés I, Jiménez-Huete A, Kurtis MM. Impact of the coronavirus disease 2019 pandemic on functional movement disorders: lessons from a specialized clinic. Mov Disord. 2020;35:1723-1724.

27. Peng EYC, Lee MB, Tsai ST, et al. Population-based post-crisis psychological distress: an example from the SARS outbreak in Taiwan. J Formos Med Assoc. 2010;109:524-532.

28. Bartholomew RE, Wessely S, James Rubin G. Mass psychogenic illness and the social network: is it changing the pattern of outbreaks? J R Soc Med. 2012;105:509-512.

29. Radford B, Bartholomew R. Pokémon contagion- photosensitive epilepsy or mass psychogenic illness? South Med J. 2001;94:197-204.

30. Gao J, Zheng P, Jia Y, et al. Mental health problems and social media exposure during COVID-19 outbreak. PLoS One. 2020:15. 


\title{
Neurology ${ }^{\circ}$ Clinical Practice
}

\author{
Increased Incidence of Functional (Psychogenic) Movement Disorders in Children and \\ Adults Amid the COVID-19 Pandemic: A Cross-sectional Study \\ Mariam Hull, Mered Parnes and Joseph Jankovic \\ Neurol Clin Pract 2021;11;e686-e690 Published Online before print April 14, 2021 \\ DOI 10.1212/CPJ.0000000000001082
}

This information is current as of April 14, 2021

\begin{abstract}
Updated Information \& Services

References

Subspecialty Collections

Permissions \& Licensing

Reprints

including high resolution figures, can be found at: http://cp.neurology.org/content/11/5/e686.full.html

This article cites 29 articles, 1 of which you can access for free at: http://cp.neurology.org/content/11/5/e686.full.html\#\#ref-list-1

This article, along with others on similar topics, appears in the following collection(s):

All Movement Disorders

http://cp.neurology.org//cgi/collection/all_movement_disorders Conversion

http://cp.neurology.org//cgi/collection/conversion

COVID-19

http://cp.neurology.org//cgi/collection/covid_19

Pediatric conversion

http://cp.neurology.org//cgi/collection/pediatric_conversion its entirety can be found online at:

http://cp.neurology.org/misc/about.xhtml\#permissions

Information about ordering reprints can be found online: http://cp.neurology.org/misc/addir.xhtml\#reprintsus
\end{abstract}

Information about reproducing this article in parts (figures,tables) or in

Neurol Clin Pract is an official journal of the American Academy of Neurology. Published continuously since 2011, it is now a bimonthly with 6 issues per year. Copyright ( 2021 American Academy of Neurology. All rights reserved. Print ISSN: 2163-0402. Online ISSN: 2163-0933.

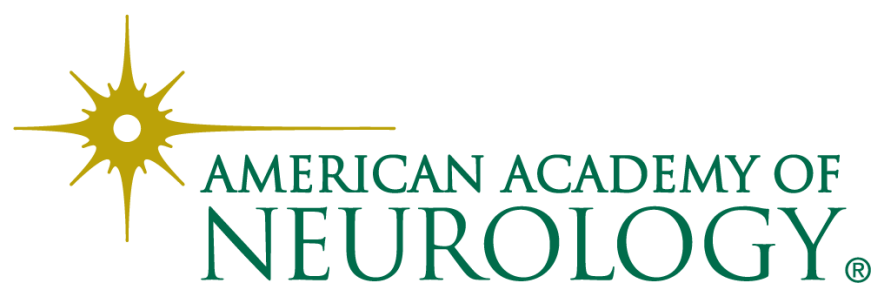

